\title{
Light Alcohol Drinking and Risk of Cancer: A Meta-Analysis of Cohort Studies
}

\author{
Yoon-Jung Choi, MD 1 \\ Seung-Kwon Myung, MD, PhD ${ }^{1,2,3}$ \\ Ji-Ho Lee, MD ${ }^{1, a}$
}

\begin{abstract}
Purpose
The purpose of this study was to determine whether light alcohol drinking increases the risk of cancer by using a meta-analysis of cohort studies because the newly revised 2015 European Code against Cancer fourth edition on alcohol and cancer was based on critical flaws in the interpretation and citation of the previous meta-analyses.
\end{abstract}

\section{Materials and Methods}

PubMed and EMBASE were searched in April, 2016. Two authors independently reviewed and selected cohort studies on the association between very light ( $\leq 0.5 \mathrm{drink} /$ day), light ( $\leq 1 \mathrm{drink} /$ day), or moderate drinking (1-2 drinks/day) and the risk of cancer incidence and mortality. A pooled relative risk with its $95 \%$ confidence interval was calculated by a randomeffects meta-analysis. Main outcome measures were cancer incidence and mortality.

\section{Results}

A total of 60 cohort studies from 135 articles were included in the final analysis. Very light drinking or light drinking was not associated with the incidence of most cancers except for female breast cancer in women and male colorectal cancer. Conversely, light drinking was associated with a decreased incidence of both female and male lung cancer significantly and both female and male thyroid cancer marginally significantly. Moderate drinking significantly increased the incidence of male colorectal cancer and female breast cancer, whereas it decreased the incidence of both female and male hematologic malignancy.

\section{Conclusion}

We found that very light or light alcohol drinking was not associated with the risk of most of the common cancers except for the mild increase in the incidence of breast cancer in women and colorectal cancer in men.

Department of Cancer Biomedical Science,

National Cancer Center Graduate School

of Cancer Science and Policy, 323 Ilsan-ro,

Ilsandong-gu, Goyang 10408, Korea

Tel: 82-31-920-0479

Fax: 82-31-920-2606

E-mail: msk@ncc.re.kr

Received February 22, 2017

Accepted May 16, 2017

Published Online May 22, 2017

aPresent address: Health Medical Center,

Gangneung Asan Hospital, Gangneung, Korea
Key words

Alcohols, Neoplasms, Cancer, Cohort studies, Meta-analysis

\section{Introduction}

Alcohol is classified as Group 1 carcinogen by the International Agency for Research on Cancer (IARC), which category is used when there is sufficient evidence of carcinogenicity in humans [1]. However, it was usually excessive alcohol drinking that was condemned for causing cancer, and light or moderate alcohol consumption has been conceived as acceptable or even encouraged because of its known benefits in preventing cardiovascular diseases. Previously in 2003, the third edition of European Code against Cancer (ECAC) recommended that "If you drink alcohol, whether beer, wine or spirits, moderate your consumption to two drinks per day if you are a man or one drink per day if you are a woman." [2,3]. In 2015, the IARC published an article involving the newly revised ECAC fourth edition on alcohol drinking and cancer, which recommends "If you drink alcohol of any type, limit your drinking. Not drinking is better for cancer prevention." [4]. 
Since the publication of the ECAC fourth edition, however, Prof. Myung, the corresponding author of this paper claimed in the letter to the editor that the new ECAC on alcohol should be corrected because there were considerable critical flaws in the interpretation and citation of the existing observational epidemiological studies and meta-analyses on the association between light alcohol drinking ( $\leq 1 \mathrm{drink} /$ day or $12.5 \mathrm{~g} /$ day) and the risk of cancer [5]. He criticized that the authors of the ECAC fourth edition did not consider the difference in findings between case-control studies and cohort studies: there was no significant association between light alcohol drinking and the risk of oropharyngeal cancer and colon cancer in the meta-analysis of cohort studies, whereas light alcohol drinking increased the risk of oropharyngeal cancer and colorectal cancer in the meta-analysis of case-control studies. Moreover, they incorrectly used the data for "moderate drinking (2-3 drinks / day)" or just "drinking" instead of "light drinking" in some analyses. Prof. Myung also published another letter to the editor [6] criticizing erroneous conclusions about the association between light alcohol drinking and the risk of cancer in Bagnardi et al.'s meta-analysis [7], which concluded that light alcohol drinking increased the risk of cancer of oropharynx, esophagus, and female breast and consequently contributed to the newly revised ECAC. Similarly, he pointed out that in Bagnardi et al.'s meta-analysis [7], except for female breast cancer, the meta-analysis of cohort studies did not show any significant association between light alcohol drinking and the risk of cancer of oropharynx, larynx, esophagus, colorectum, and liver, whereas the meta-analysis of case-control studies showed a significant positive association between light drinking and cancer of oropharynx and esophagus [6]. In summary, regarding the association between light alcohol drinking and the risk of cancer, the previous meta-analysis and the new ECAC fourth edition led to erroneous conclusions and incorrect recommendations due to the wrong interpretation and citations of the existing observational epidemiological studies.

Thus, we performed a comprehensive meta-analysis of cohort studies on this topic in order to investigate whether or not very light or light alcohol drinking as well as moderate alcohol drinking increased the risk of cancer.

\section{Materials and Methods}

\section{Search strategy}

We searched PubMed and EMBASE in March 31, 2016 using keywords "alcohol consumption," "alcohol intake," "cancer," and "cohort study." We also reviewed the bibliographies of relevant articles to find additional studies.

\section{Selection criteria}

We included prospective or retrospective cohort studies reporting a multivariate adjusted relative risk (RR) with its 95\% confidence interval (CI) for the association between light alcohol drinking ( $\leq 1 \mathrm{drink} /$ day) and/or moderate alcohol drinking (1-2 drinks / day) and the risk of cancer. The current analysis involved general healthy populations. Thus, we excluded studies involving patients with underlying cancer and populations at high risk for a specific cancer such as patients with liver cirrhosis or hepatitis B virus carriers at high risk for liver cancer and those with Barrett's esophagus at high risk for esophageal cancer. Also, we excluded (1) studies that adjusted for only age and/or sex in the multivariate analysis, (2) studies that used 0-2 drinks / day as criteria for light alcohol drinking instead of 1-2 drinks / day, and (3) studies that used $0.5 \mathrm{drink} /$ day or more as a reference value.

\section{Selection of relevant studies}

Two authors (Y.-J. Choi and J.-H. Lee) of the current study independently selected relevant studies in the first screening process. Any disagreements were solved by discussion and in consult with a third author (S.-K. Myung). If data were duplicated or shared in more than one article, we included the more comprehensive or more recently published article for the analysis.

\section{Main analysis and subgroup analysis}

We investigated the risk of each type of cancer in both incidence and mortality according to different levels of alcohol drinking: very light drinking ( $\leq 0.5$ drink/day), light drinking ( $\leq 1$ drink/day), and moderate drinking (1-2 drinks / day). In general, one drink of alcohol corresponds to one unit of alcohol (12.5 g) which is contained in one glass of beer (355 mL), one glass of wine, and a single shot of hard liquor. However, since a number of studies used up to $15 \mathrm{~g} /$ day as 1 drink/day, we accepted up to $15 \mathrm{~g}$ as 1 drink of alcohol. The 7 drinks/wk, 105 g/wk, 30 drinks / mo, and 15 ounce/ mo were considered equivalent to $1 \mathrm{drink} /$ day or light drinking. Likewise, 3.5 drink/wk, 52.5 g/wk, 15 drinks / mo, and 7.5 ounce / mo were considered as 0.5 drink/ day or very light drinking. Also, 15-30 g/day, 7-14 drinks/wk, 105-210 $\mathrm{g} / \mathrm{wk}, 30-60$ drinks/mo, and 15-30 ounce/mo were categorized to 1 to 2 drinks / day or moderate drinking. We chose the upper limit of the range of drinking to categorize levels of drinking: 5-15 g/day of drinking was considered as light 


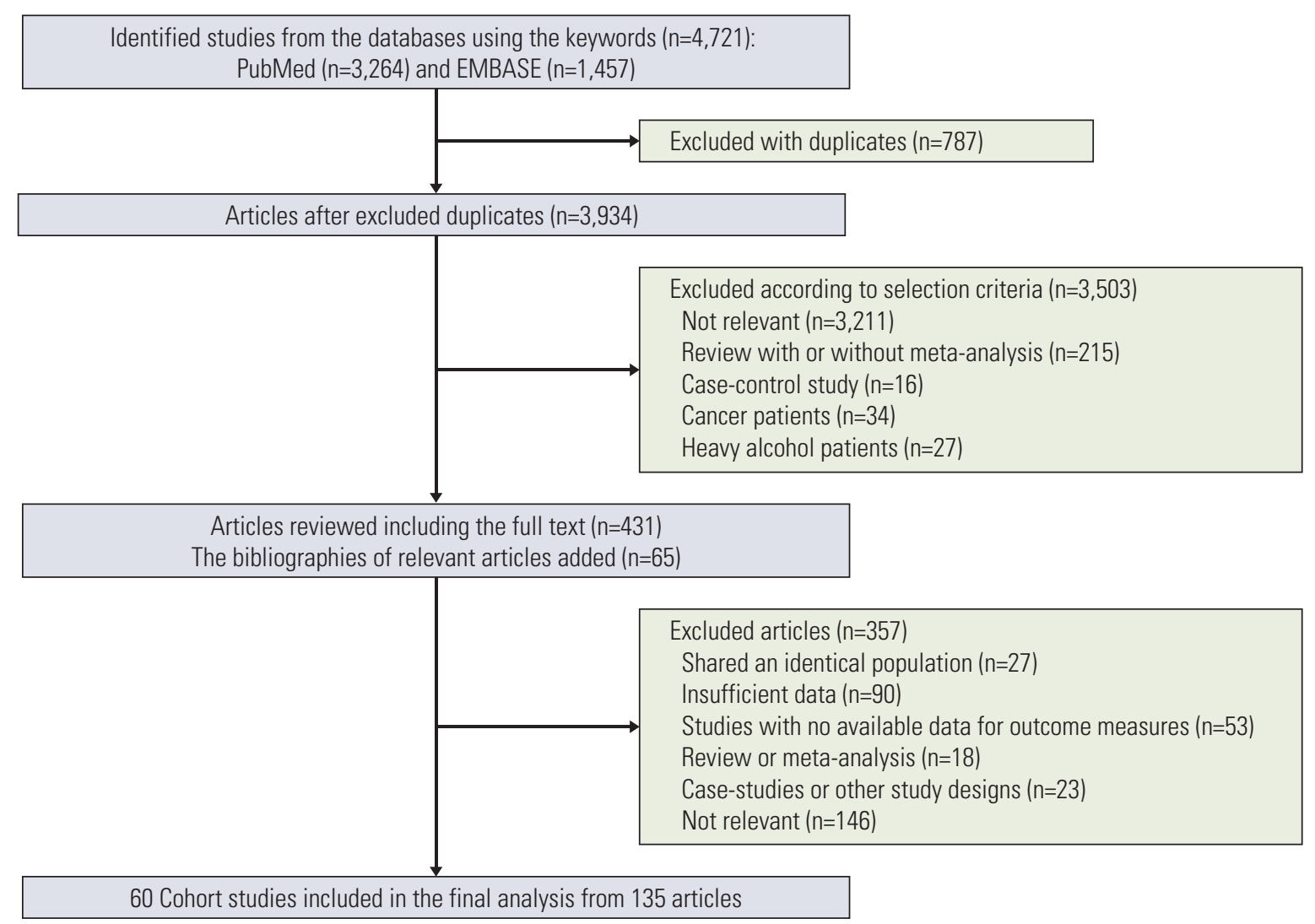

Fig. 1. Flow diagram of identification of relevant studies.

drinking; if the upper limit exceeded $15 \mathrm{~g} /$ day, then it was categorized as moderate drinking. We performed the subgroup meta-analysis by type of cancer and gender.

\section{Assessment of methodological quality of included stud- ies}

The methodological quality of the included studies was based on the Newcastle-Ottawa Scale (NOS) [8]. This scale has a star system (range, 0 to 9 stars) for the assessment. Standard criteria for high quality have not been established. Regarding outcome assessment, a star was given for a follow-up period of $\geq 5$ years and a follow-up rate of $\geq 90 \%$.

\section{Statistical analysis}

We used the adjusted RR with its 95\% CI in order to compute a pooled RR with its 95\% CI. Heterogeneity was assessed by Higgins $\mathrm{I}^{2}$, which is the percentage of total variation across the studies as follows:

$$
\mathrm{I}^{2}=100 \% \times(\mathrm{Q}-\mathrm{df}) / \mathrm{Q},
$$

where $\mathrm{df}$ refers to degrees of freedom, and $\mathrm{Q}$ refers to Cochran's heterogeneity statistics [9]. An $\mathrm{I}^{2}$ value lies between $0 \%$ (no observed heterogeneity) and 100\% (maximal heterogeneity). In general, an $\mathrm{I}^{2}$ greater than $50 \%$ is considered to have substantial heterogeneity. We used a randomeffects model meta-analysis based on the DerSimonian and Laird method because most cohort studies were conducted in the different populations [10,11]. A STATA ver. 13.1 software (StataCorp LP, College Station, TX) was used for statistical analysis.

\section{Results}

\section{Selection of relevant studies}

Fig. 1 shows a flow diagram of how we selected relevant studies. We identified a total of 4,721 articles consisting of 3,264 articles from PubMed and 1,457 articles from EMBASE. We excluded 787 duplicate articles and 3,503 articles that did 
Table 1. Number of articles and studies by organ site and country among 135 articles and 60 cohort studies

\begin{tabular}{|c|c|c|c|c|}
\hline \multirow{2}{*}{ Category } & \multicolumn{2}{|c|}{ Incidence } & \multicolumn{2}{|c|}{ Mortality } \\
\hline & No. of articles & No. of studies & No. of articles & No. of studies \\
\hline \multicolumn{5}{|l|}{ Site of cancer } \\
\hline \multicolumn{5}{|l|}{ Upper digestive tract } \\
\hline Oral and pharynx & 5 & 5 & 2 & 2 \\
\hline Esophagus (SCC) & 2 & 2 & 5 & 4 \\
\hline Esophagus (ADC) and cardia & 3 & 3 & NA & NA \\
\hline Head and neck & 2 & 2 & NA & NA \\
\hline \multicolumn{5}{|l|}{ Gastrointestinal tract } \\
\hline Stomach (non-cardia) & 11 & 9 & 2 & 2 \\
\hline Colorectum & 16 & 16 & 6 & 5 \\
\hline Colon & 10 & 10 & NA & NA \\
\hline Rectum & 9 & 9 & & \\
\hline \multicolumn{5}{|l|}{ Hepatobiliary system } \\
\hline Liver & 2 & 2 & 2 & 2 \\
\hline Pancreas & 5 & 5 & 4 & 4 \\
\hline Gallbladder & NA & NA & 1 & 1 \\
\hline \multicolumn{5}{|l|}{ Respiratory tract } \\
\hline Lung & 10 & 10 & 6 & 5 \\
\hline Larynx & 1 & 1 & 1 & 1 \\
\hline \multicolumn{5}{|l|}{ Women's cancer } \\
\hline Breast (female) & 34 & 27 & 7 & 7 \\
\hline Endometrium & 9 & 9 & NA & NA \\
\hline Ovary & 5 & 5 & NA & NA \\
\hline Cervix/Uterus & 2 & 2 & 1 & 1 \\
\hline \multicolumn{5}{|l|}{ Men's cancer } \\
\hline Prostate & 15 & 14 & 4 & 4 \\
\hline \multicolumn{5}{|l|}{ Urological system } \\
\hline Kidney & 7 & 7 & 1 & 1 \\
\hline Bladder & 4 & 4 & NA & NA \\
\hline \multicolumn{5}{|l|}{ Others } \\
\hline Thyroid & 6 & 6 & NA & NA \\
\hline Hematologic malignancy & 8 & 8 & 2 & 2 \\
\hline Malignant melanoma & 3 & 3 & NA & NA \\
\hline \multicolumn{5}{|l|}{ Country } \\
\hline \multicolumn{5}{|l|}{ Asia } \\
\hline China & 3 & 2 & NA & NA \\
\hline Japan & 5 & 4 & 2 & 2 \\
\hline Korea & 3 & 2 & 1 & 1 \\
\hline Singapore & 3 & 1 & NA & NA \\
\hline Honk Kong & NA & NA & 1 & 1 \\
\hline \multicolumn{5}{|l|}{ North America } \\
\hline US & 70 & 28 & 9 & 9 \\
\hline Canada & 4 & 2 & 1 & 1 \\
\hline
\end{tabular}

(Continued to the next page)

not meet the selection criteria after reviewing 3,934 articles based on titles and abstracts. After reviewing the full text of the remaining 431 articles along with additional 65 articles newly located from relevant bibliographies, 361 articles were excluded because of studies sharing an identical population $(\mathrm{n}=27)$, insufficient data $(\mathrm{n}=94)$, studies with no available data for outcome measures $(n=53)$, review or meta-analysis $(n=18)$, case-studies or other study designs $(n=23)$, and no relevant 
Table 1. Continued

\begin{tabular}{|c|c|c|c|c|}
\hline \multirow{2}{*}{ Category } & \multicolumn{2}{|c|}{ Incidence } & \multicolumn{2}{|c|}{ Mortality } \\
\hline & No. of articles & $\overline{\text { No. of studies }}$ & No. of articles & No. of studies \\
\hline \multicolumn{5}{|l|}{ Europe } \\
\hline UK & 5 & 5 & NA & NA \\
\hline Sweden & 6 & 3 & NA & NA \\
\hline Norway & 1 & 1 & NA & NA \\
\hline Netherland & 10 & 3 & NA & NA \\
\hline Lithuania & 2 & 2 & NA & NA \\
\hline France & 2 & 2 & NA & NA \\
\hline Finland & 1 & 1 & NA & NA \\
\hline European countries & 1 & 1 & NA & NA \\
\hline Denmark & 5 & 3 & NA & NA \\
\hline
\end{tabular}

SCC, squamous cell carcinoma; ADC, adenocarcinoma; NA, not available.

studies ( $\mathrm{n}=146)$. From a total of 135 articles, 60 cohort studies were included in the final analysis (references of 135 articles are presented in Supplementary Material).

\section{Characteristics of studies included in the final analysis}

All the 60 cohort studies included in the final analysis involved a total of 9,428,076 participants $(5,478,133$ women and $3,949,943$ men). As an outcome measure, all studies reported cancer incidence, and 14 studies reported cancer mortality. The number of studies according to cancer organ site were as follows (incidence, mortality): oral cavity and oropharynx ( $n=5, n=2)$, esophagus (squamous cell carcinoma) $(\mathrm{n}=2)$, esophagus (adenocarcinoma) and cardia $(\mathrm{n}=3)$, stomach $(\mathrm{n}=9, \mathrm{n}=2)$, colorectum $(\mathrm{n}=16, \mathrm{n}=5)$, liver $(\mathrm{n}=2, \mathrm{n}=2)$, pancreas $(n=5, n=4)$, lung cancer $(n=10, n=5)$, female breast $(n=27, n=7)$, endometrium $(n=9)$, ovary $(n=5)$, prostate $(n=14, n=4)$, kidney $(n=7, n=1)$, bladder $(n=4)$, hematologic malignancies $(n=8$, $\mathrm{n}=2$ ), and skin (malignant melanoma) $(\mathrm{n}=3)$ (Table 1$)$.

Studies were conducted in North America $(n=30, n=10)$, Europe ( $n=21)$, and Asia ( $n=9, n=4)$ (Table 1). General characteristics of the studies included in the final analysis by cancer incidence and mortality are presented in S1 and S2 Tables.

\section{Methodological quality of studies}

S3 and S4 Tables show the methodological quality of the studies included in the analysis. The range of scores was 5 to 9 for cancer incidence and 6-8 for cancer mortality. The mean score was 6.8 for cancer incidence studies $(\mathrm{n}=121)$ and 6.9 for cancer mortality studies $(\mathrm{n}=14)$.

\section{Very light alcohol drinking and the risk of cancer}

\section{1) Incidence}

Table 2 shows the associations between cancer incidence and very light, light, and moderate alcohol drinking. Overall very light drinking ( $\leq 0.5$ drink / day) was not associated with the incidence of most cancers. However, very light drinking was significantly associated with a decreased incidence of both female and male lung cancer (RR, $0.89 ; 95 \%$ CI, 0.84 to 0.93 ; $\mathrm{I}^{2}=6.9 \% ; \mathrm{n}=3$ ), female lung cancer (RR, $0.82 ; 95 \% \mathrm{CI}, 0.70$ to $\left.0.95 ; \mathrm{I}^{2}=12.9 \% ; \mathrm{n}=2\right)$, whereas it increased the incidence of female breast cancer (RR, 1.04; 95\% CI, 1.01 to $1.07 ; \mathrm{I}^{2}=3.7 \%$; $\mathrm{n}=20$ ). There was no significant association between very light drinking and the incidence of head and neck cancer, esophageal cancer, stomach cancer, colorectal cancer, pancreatic cancer, endometrial cancer, ovary cancer, prostate cancer, kidney cancer, bladder cancer, thyroid cancer, and hematologic malignancy.

\section{2) Mortality}

Table 3 shows the associations between cancer mortality and very light, light, and moderate alcohol drinking. Very light drinking reduced the mortality of both female and male lung cancer (RR, $0.81 ; 95 \% \mathrm{CI}, 0.69$ to $0.94 ; \mathrm{I}^{2}=0.0 \%$; $\left.\mathrm{n}=2\right)$, female lung cancer (RR, $0.70 ; 95 \% \mathrm{CI}, 0.56$ to $0.89 ; \mathrm{n}=1)$ and female breast cancer (RR, $0.79 ; 95 \% \mathrm{CI}, 0.64$ to $0.97 ; \mathrm{I}^{2}=0.0 \%$; $\mathrm{n}=2$ ). There was no significant association between very light drinking and the mortality of colorectal cancer, gallbladder cancer, prostate cancer, and hematologic malignancy. 


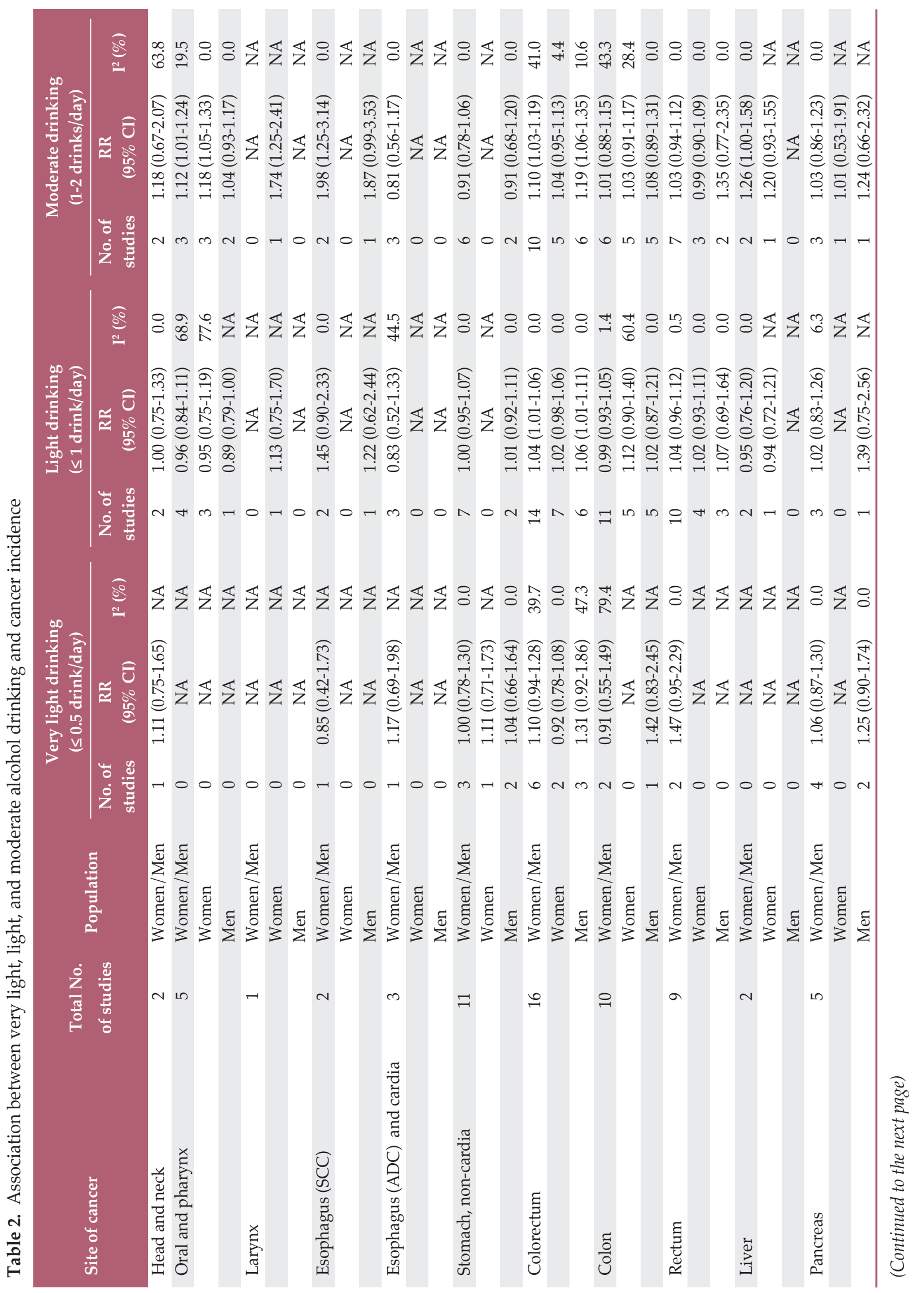




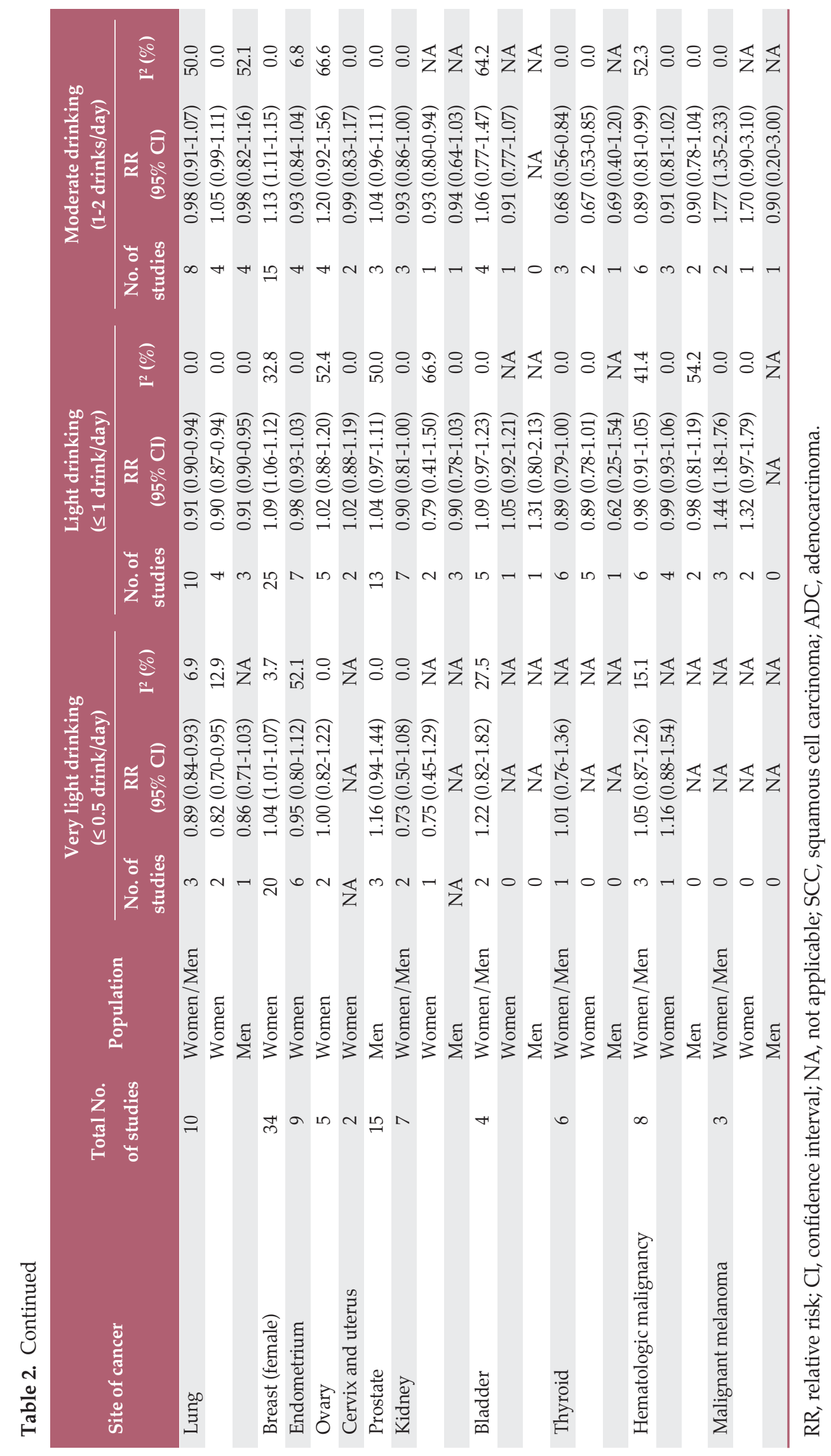




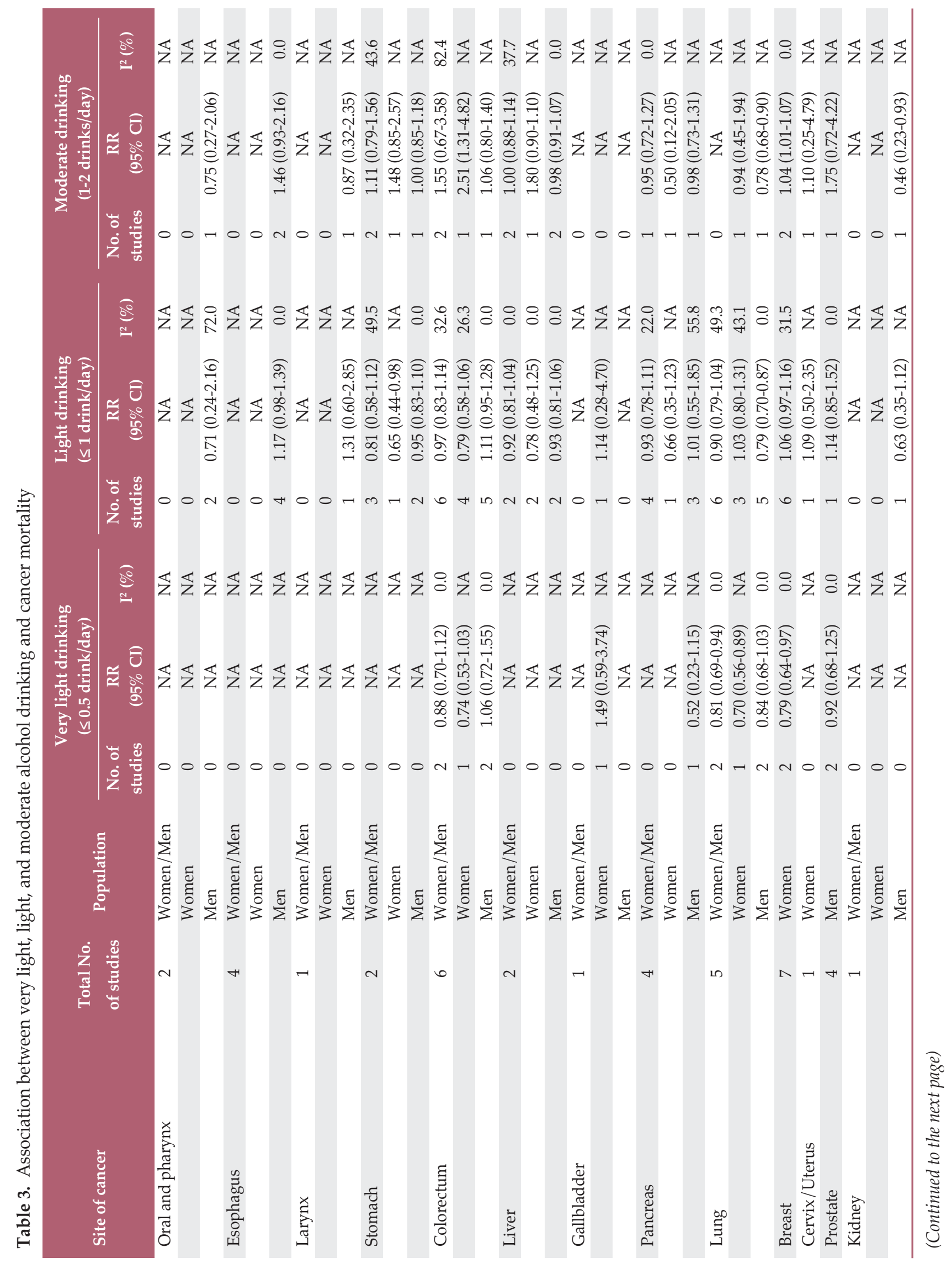




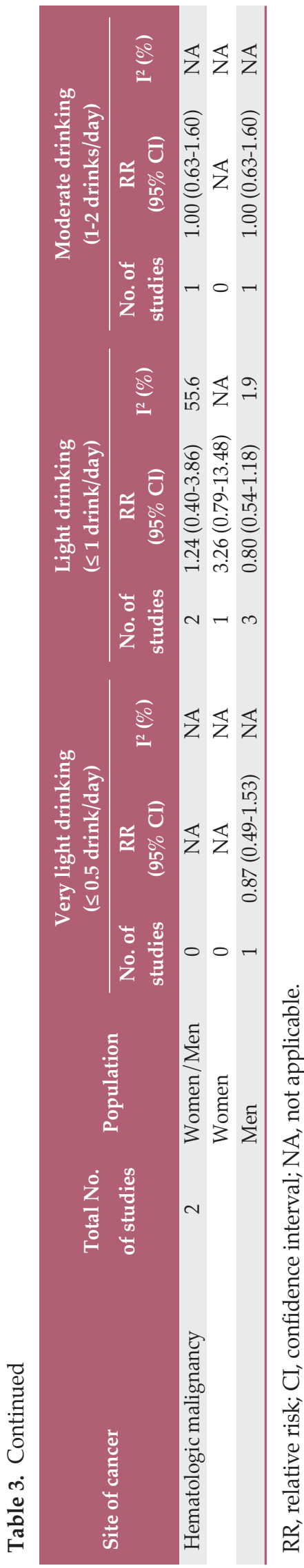

\section{Light alcohol drinking and the risk of cancer}

\section{1) Incidence}

As shown in Table 2, similar to the findings of very light alcohol drinking, overall light drinking ( $\leq 1$ drink/day) was not associated with the incidence of most cancers. However, light drinking was significantly associated with a decreased incidence of both female and male lung cancer (RR, 0.91; 95\% CI, 0.90 to $\left.0.94 ; I^{2}=0.0 \% ; n=10\right)$, male lung cancer ( $R R, 0.91 ; 95 \%$ $\mathrm{CI}, 0.90$ to $0.95 ; \mathrm{I}^{2}=0.0 \% ; \mathrm{n}=3$ ), and female lung cancer (RR, 0.90 ; $95 \%$ CI, 0.87 to $0.94 ; \mathrm{I}^{2}=0.0 \%$; $\mathrm{n}=4$ ), whereas it increased the incidence of female breast cancer (RR, 1.09; 95\% CI, 1.06 to 1.12; $\mathrm{I}^{2}=32.8 \% ; \mathrm{n}=25$ ) (Fig. 2), both female and male colorectal cancer (RR, 1.04; 95\% CI, 1.01 to $1.06 ; \mathrm{I}^{2}=0.0 ; \mathrm{n}=14$ ), male colorectal cancer (RR, 1.06; 95\% CI, 1.01 to $1.11 ; \mathrm{I}^{2}=0.0 \%$; $\mathrm{n}=6$ ) (Fig. 3), and both female and male malignant melanoma (RR, $1.44 ; 95 \% \mathrm{CI}, 1.18$ to $\left.1.76 ; \mathrm{I}^{2}=0.0 \% ; \mathrm{n}=3\right)$. In the subgroup metaanalysis by type of male colorectal cancer, light drinking was not associated with the incidence of either colon cancer (RR, $1.02 ; 95 \% \mathrm{CI}, 0.87$ to $1.21 ; \mathrm{I}^{2}=0.0 \%$; $\mathrm{n}=5$ ) or rectal cancer (RR, $1.07 ; 95 \% \mathrm{CI}, 0.69$ to $1.64 ; \mathrm{I}^{2}=0.0 \%$; $\mathrm{n}=3$ ). Also, light drinking was marginally associated with a decreased incidence of both female and male thyroid cancer (RR, $0.89 ; 95 \% \mathrm{CI}, 0.79$ to 1.00 ; $\left.\mathrm{I}^{2}=0.0 \% ; \mathrm{n}=6\right)$. There was no significant association between light drinking and the incidence of oropharyngeal cancer, head and neck cancer, esophageal cancer, stomach cancer, liver cancer, pancreatic cancer, endometrial cancer, ovary cancer, prostate cancer, kidney cancer, bladder cancer, and hematologic malignancy.

\section{2) Mortality}

As shown in Table 3, light drinking reduced the mortality of female stomach cancer (RR, $0.65 ; 95 \% \mathrm{CI}, 0.44$ to $0.98 ; \mathrm{n}=1$ ) and male lung cancer (RR, $0.79 ; 95 \% \mathrm{CI}, 0.70$ to $0.87 ; \mathrm{I}^{2}=0.0 \%$; $\mathrm{n}=5$ ). There was no significant association between light drinking and the mortality of oropharyngeal cancer, esophageal cancer, larynx cancer, colorectal cancer, liver cancer, female gallbladder cancer, pancreatic cancer, breast cancer, cervical cancer, prostate cancer, and hematologic malignancy.

\section{Moderate alcohol drinking and the risk of cancer}

\section{1) Incidence}

As shown in Table 2, moderate drinking (1-2 drinks/day) increased the incidence of both female and male oropharyngeal cancer (RR, 1.12; 95\% CI, 1.01 to $1.24 ; \mathrm{I}^{2}=19.5 \%$; $\mathrm{n}=3$ ), female oropharyngeal cancer (RR, 1.18; 95\% CI, 1.05 to 1.33; $\mathrm{I}^{2}=0.0 \%$; $\mathrm{n}=3$ ), female larynx cancer ( $\mathrm{RR}, 1.74 ; 95 \% \mathrm{CI}, 1.25$ to $2.41 ; \mathrm{n}=1)$, both female and male squamous cell esophageal 


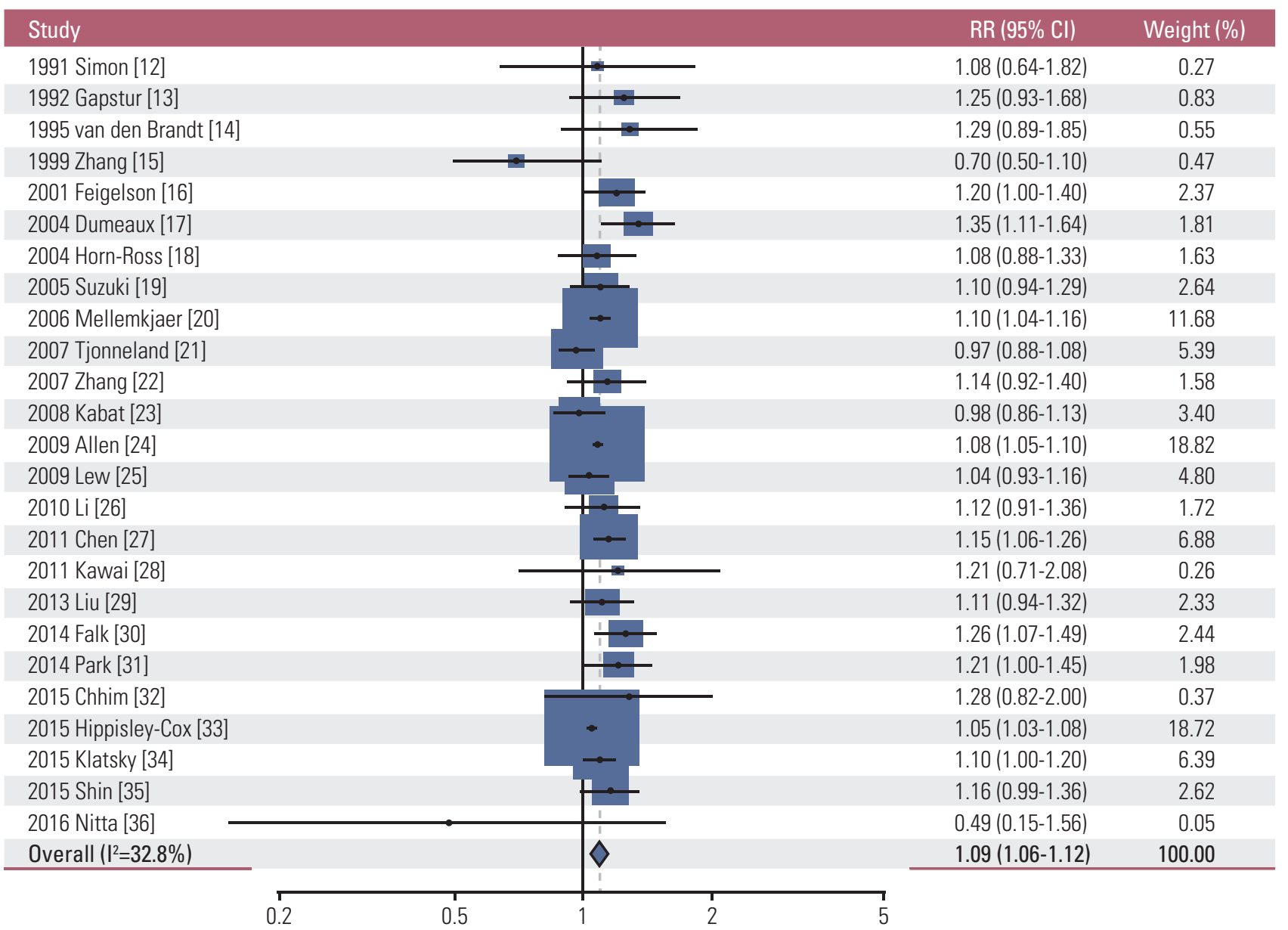

Fig. 2. Association between light alcohol drinking ( $\leq 1$ drink/day) and the risk of female breast cancer in a random-effects meta-analysis. RR, relative risk; $\mathrm{CI}$, confidence interval.

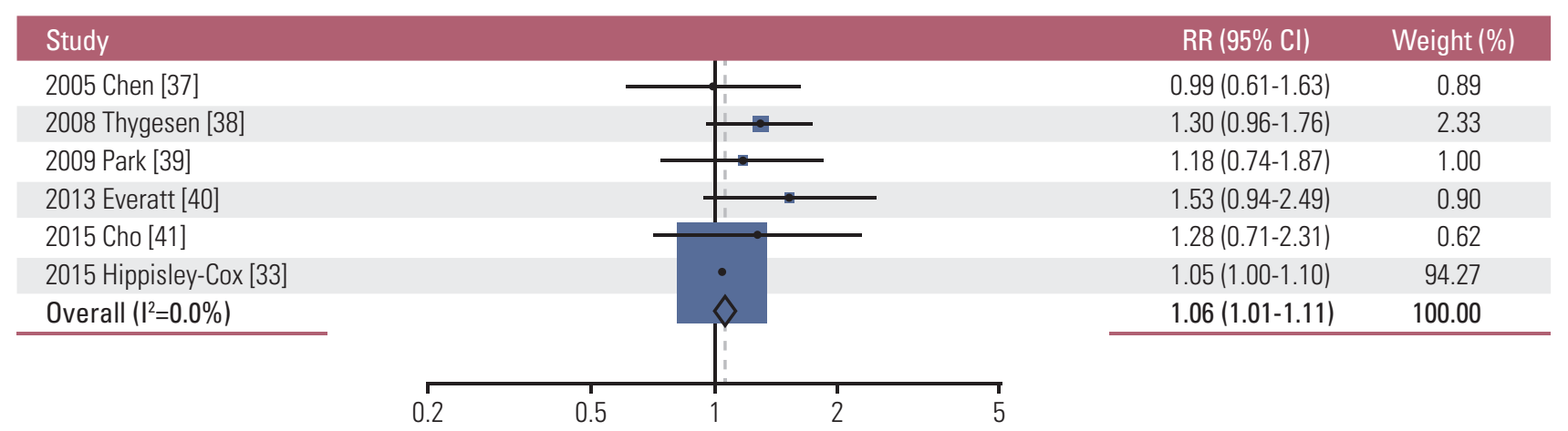

Fig. 3. Association between light alcohol drinking ( $\leq 1$ drink/day) and the risk of male colorectal cancer in a random-effects meta-analysis. RR, relative risk; CI, confidence interval. 
cancer (RR, $1.98 ; 95 \% \mathrm{CI}, 1.25$ to $3.14 ; \mathrm{I}^{2}=0.0 \% ; \mathrm{n}=2$ ), both female and male colorectal cancer (RR, 1.10; 95\% CI, 1.03 to 1.19; $\left.\mathrm{I}^{2}=41.0 \% ; \mathrm{n}=6\right)$, male colorectal cancer $(\mathrm{RR}, 1.19 ; 95 \% \mathrm{CI}$, 1.06 to $\left.1.35 ; \mathrm{I}^{2}=10.6 \% ; \mathrm{n}=6\right)$, female breast cancer ( $\mathrm{RR}, 1.13 ; 95 \%$ CI, 1.11 to $\left.1.15 ; \mathrm{I}^{2}=0 \% ; \mathrm{n}=15\right)$, and both female and male malignant melanoma (RR, 1.77; 95\% CI, 1.35 to $2.33 ; \mathrm{I}^{2}=0.0 \%$; $\mathrm{n}=2$ ). Also, it was marginally significantly associated with an increased incidence of female and male liver cancer $(R R, 1.26$; $95 \% \mathrm{CI}, 1.00$ to $1.58 ; \mathrm{I}^{2}=0.0 \%$; $\mathrm{n}=2$ ). On the contrary, moderate drinking reduced the incidence of both female and male kidney cancer ( $R R, 0.93 ; 95 \%$ CI, 0.86 to $1.00 ; \mathrm{I}^{2}=0.0 \%$; $\mathrm{n}=3$ ), female kidney cancer (RR, $0.93 ; 95 \% \mathrm{CI}, 0.80$ to $0.94 ; \mathrm{n}=1$ ), both female and male thyroid cancer ( $\mathrm{RR}, 0.68 ; 95 \% \mathrm{CI}, 0.56$ to 0.84 ; $\mathrm{I}^{2}=0.0 \% ; \mathrm{n}=3$ ), female thyroid cancer ( $\mathrm{RR}, 0.67 ; 95 \% \mathrm{CI}, 0.53$ to $0.85 ; \mathrm{I}^{2}=0.0 \% ; \mathrm{n}=2$ ), and both female and male hematologic malignancy (RR, 0.89; 95\% CI, 0.81 to $0.99 ; \mathrm{I}^{2}=52.3 \%$; $\mathrm{n}=6$ ). There was no significant association between moderate drinking and the incidence of head and neck cancer, adenomatous esophageal cancer and cardia, stomach cancer, pancreatic cancer, lung cancer, endometrial cancer, ovary cancer, prostate cancer, and bladder cancer.

\section{2) Mortality}

As shown in Table 3, overall moderate drinking was not associated with the mortality of most cancers. However, it increased the mortality of female colorectal cancer (RR, 2.51; $95 \% \mathrm{CI}, 1.31$ to $4.82 ; \mathrm{n}=1)$ and female breast cancer (RR, 1.04; $95 \% \mathrm{CI}, 1.01$ to $\left.1.07 ; \mathrm{I}^{2}=0.0 \% ; \mathrm{n}=2\right)$, while it reduced the mortality of male kidney cancer (RR, $0.46 ; 95 \% \mathrm{CI}, 0.23$ to 0.93 ; $\mathrm{n}=1$ ).

\section{Discussion}

\section{Principal findings}

In the current large scale meta-analysis of cohort studies, we found that compared with nondrinking or occasional alcohol drinking, very light ( $\leq 0.5$ drink/day) or light $(\leq 1$ drink/day did not increase the incidence of most cancers except for female breast cancer and male colorectal cancer by up to $9 \%$ and $6 \%$, respectively. Conversely, light drinking was associated with a decreased incidence of both female and male lung cancer significantly and both female and male thyroid cancer marginally significantly. In the meantime, moderate drinking, i.e., 1 to 2 drink/day significantly increased the incidence of two types of cancer, male colorectal cancer and female breast cancer, whereas it decreased the incidence of both female and male hematologic malignancy.
Also, there is a limitation to draw definite conclusions on the associations between very light or light drinking and the risk of several types of cancer such as lung cancer, malignant melanoma, and rectal cancer in incidence along with those associations in mortality and the associations between moderate drinking and the risk of most cancers except for male colorectal cancer, female breast cancer, and hematologic malignancy in both incidence and mortality because of a paucity of the included studies.

\section{Comparison with previous findings}

Our conclusion on the association between light drinking and the risk of cancer are inconsistent with those from a previous large scale meta-analysis of observational epidemiological studies. Bagnardi et al.'s meta-analysis [7] of 222 articles which included case-control studies and cohort studies published before December 2010 concluded that light drinking (1 drink/day) increased the risk of cancer of oral cavity, pharynx, esophagus, and female breast [6]. As mentioned before in the introduction section, however, they did not consider the difference in findings between case-control studies and cohort studies and drew a wrong conclusion based on the findings from combining the results of both case-control studies and cohort studies. As Prof. Myung pointed out in his letter, except for breast cancer, the subgroup meta-analysis of cohort studies which generally provide a higher level of evidence than case-control studies did not show any significant association between light alcohol drinking and the risk of cancers of oral cavity, pharynx, and esophagus although light drinking was significantly associated with the increased risk of these cancers in the subgroup meta-analysis of case-control studies. Therefore, Bagnardi et al.'s meta-analysis [7] should have concluded that overall light drinking was not associated with the risk of cancer, although it increased the risk of female breast cancer slightly.

After the publication of Bagnardi et al.'s meta-analysis [7], the 2015 newly revised ECAC fourth edition changed its recommendation on drinking from "Moderate your consumption to two drinks per day if you are a man or one drink per day if you are a woman" to "Not drinking is better for cancer prevention" based on the similar conclusions to those from Bagnardi et al. [7]. The ECAC fourth edition also did not consider the difference in findings between case-control studies and cohort studies and moreover wrongly used data for moderate drinking or just drinking instead of light drinking for the meta-analysis.

\section{Meaning and implications of the current findings for policy makers and clinicians}

In our study, except for only two types of cancer, female 
breast cancer and male colorectal cancer, very light or light drinking was not associated with the risk of most cancers. Although the incidence of malignant melanoma was increased with light drinking, it remains inconclusive due to a small number of included studies. As for female breast cancer, its incidence was increased at even the level of very light drinking ( $\leq 0.5$ drink/day), which can be interpreted that there is no safe level for alcohol drinking regarding female breast cancer. Also, light drinking ( $\leq 1$ drink/day) was associated with the increased incidence of male colorectal cancer. However, except for these two types of cancer, there was no sufficient evidence to support that very light or light drinking up to $1 \mathrm{drink} /$ day increases the risk of most of cancers. On the contrary, light drinking significantly decreased the incidence of both female and male lung cancer significantly and thyroid cancer marginally significantly. Thus, our findings imply that very light or light drinking has both benefits and harms in cancer prevention according to types of cancers.

\section{Possible mechanisms for the main findings}

The possible mechanisms on the association between alcohol consumption and the risk of breast cancer include the effect of alcohol on estrogen levels and estrogen receptor in mammary epithelial cells, the carcinogenic effect of ethanol metabolites, the effect of ethanol on epigenetic regulation of gene expression in the breast [42]. As for colon cancer, potential mechanisms to be examined in human-based studies are acetaldehyde production in the colon, cell proliferation due to ethanol or acetaldehyde exposure, and alterations in DNA repair mechanisms [43]. However, it still remains unclear why even very light or light drinking levels increase the incidence of female breast cancer and male colorectal cancer unlike the remaining common cancers.

In the meantime, very light or light drinking was associated with the decreased incidence of lung cancer significantly and thyroid cancer marginally significantly. It has been suggested that the protective effect of low or moderate alcohol consumption on lung cancer is attributable to its anti-inflammatory effects through lower plasma concentration of several systemic biomarkers of inflammation compared with no consumption [44], antioxidant effects in tumor promotion and progression [45], and anti-carcinogenic effects through induction of protective enzymes such as carcinogen detoxification enzymes [46,47]. However, it remains unclear why these effects would be specific for lung cancer. Also, the possible biological mechanisms on the inverse association between alcohol consumption and the risk of thyroid cancer are the protective effect on developing thyroid cancer by decreased levels of thyroid-stimulating hormone and the direct toxic effect on thyroid cells and consequently reduction of thyroid volume [48].

\section{Strengths of the current meta-analysis}

This is the first meta-analysis of cohort studies that comprehensively investigated the association between very light and light alcohol drinking and the risk of a variety of cancers. Our study has its originality in that for the first time, we claim that overall light alcohol drinking is not associated with the risk of most of the common cancers except for female breast cancer and male colorectal cancer. Our findings refute the newly revised ECAC fourth edition on alcohol drinking and cancer and those from Bagnardi et al.'s metaanalysis [7].

\section{Limitations}

There are several limitations in our study. First, except for breast cancer, colorectal cancer, and lung cancer, due to a paucity of data on very light or light drinking for most cancers, we were unable to clearly evaluate the associations between very light or light drinking and most cancers. Thus, further studies are necessary to confirm these associations. Second, there might be possible interactions between drinking and other factors such as smoking on the development of breast cancer and colorectal cancer. Although all the included cohort studies adjusted various factors in each multivariable analysis, those factors varied across the studies. For example, however, because most studies included the important factors affecting the development of breast cancer such as age, smoking, age at menopause, age at first birth, family history of breast cancer, hormone replacement therapy, and oral contraceptives, the effect of other unknown confounding factors would be minimal. Last, the generalization of our findings is limited because a small number of cohort studies among Asian populations were included in our analysis. More cohort studies are required to investigate that our findings can be applied to Asian populations.

Our meta-analysis of cohort studies found that compared with non or occasional alcohol drinking, very light or light drinking was not associated with the risk of most cancers except for female breast cancer and male colorectal cancer with a small increase in incidence. Although the IARC re-published The ECAC 4th Edition: Alcohol Drinking and Cancer in December 2016 [49] with a few corrections of data cited on the association between light alcohol drinking and cancer risk, they still did not consider the difference in findings between case-control studies and cohort studies and stick to the previously revised recommendation. Therefore, we suggest that the revision of the current ECAC fourth edition on alcohol drinking and cancer should be seriously considered from "If you drink alcohol of any type, limit your drinking. Not drinking is better for cancer prevention" to "If you drink alcohol of any type, limit your drinking. Not drinking is bet- 
ter in order to prevent breast cancer in women and colorectal cancer in men."

\section{Electronic Supplementary Material}

Supplementary materials are available at Cancer Research and Treatment website (http://www.e-crt.org).

\section{Conflicts of Interest}

Conflict of interest relevant to this article was not reported.

\section{References}

1. IARC Working Group on the Evaluation of Carcinogenic Risks to Humans. Personal habits and indoor combustions. Volume 100 E. A review of human carcinogens. IARC Monogr Eval Carcinog Risks Hum. 2012;100(Pt E):1-538.

2. Boyle P, Autier P, Bartelink H, Baselga J, Boffetta P, Burn J, et al. European Code Against Cancer and scientific justification: third version (2003). Ann Oncol. 2003;14:973-1005.

3. Schuz J, Espina C, Villain P, Herrero R, Leon ME, Minozzi S, et al. European Code against Cancer 4th Edition: 12 ways to reduce your cancer risk. Cancer Epidemiol. 2015;39 Suppl 1: S1-10.

4. Scoccianti C, Cecchini M, Anderson AS, Berrino F, BoutronRuault MC, Espina C, et al. European code against cancer 4th edition: alcohol drinking and cancer. Cancer Epidemiol. 2015;39 Suppl 1:S67-74.

5. Myung SK. Insufficient evidence on the association between light alcohol drinking and the risk of cancer: on the need for correction of the newly revised European Code against Cancer 4th edition. Cancer Epidemiol. 2016;44:174-5.

6. Myung SK. Erroneous conclusions about the association between light alcohol drinking and the risk of cancer: comments on Bagnardi et al.'s meta-analysis. Ann Oncol. 2016;27:2138.

7. Bagnardi V, Rota M, Botteri E, Tramacere I, Islami F, Fedirko $\mathrm{V}$, et al. Light alcohol drinking and cancer: a meta-analysis. Ann Oncol. 2013;24:301-8.

8. Wells GA, Shea B, O'Connell D, Peterson J, Welch V, Losos M, et al. The Newcastle-Ottawa Scale (NOS) for assessing the quality of nonrandomised studies in meta-analyses [Internet]. Ottawa: Ottawa Hospital Research Institute; 2017 [cited 2017 May 2]. Available from: http://www.ohri.ca/programs/clinical_epidemiology/oxford.asp.

9. Higgins JP, Thompson SG. Quantifying heterogeneity in a meta-analysis. Stat Med. 2002;21:1539-58.

10. DerSimonian R, Laird N. Meta-analysis in clinical trials. Control Clin Trials. 1986;7:177-88.

11. Borenstein M, Hedges LV, Higgins JP, Rothstein HR. A basic introduction to fixed-effect and random-effects models for meta-analysis. Res Synth Methods. 2010;1:97-111.

12. Simon MS, Carman W, Wolfe R, Schottenfeld D. Alcohol consumption and the risk of breast cancer: a report from the Tecumseh Community Health Study. J Clin Epidemiol.
1991;44:755-61.

13. Gapstur SM, Potter JD, Sellers TA, Folsom AR. Increased risk of breast cancer with alcohol consumption in postmenopausal women. Am J Epidemiol. 1992;136:1221-31.

14. van den Brandt PA, Goldbohm RA, van 't Veer P. Alcohol and breast cancer: results from The Netherlands Cohort Study. Am J Epidemiol. 1995;141:907-15.

15. Zhang Y, Kreger BE, Dorgan JF, Splansky GL, Cupples LA, Ellison RC. Alcohol consumption and risk of breast cancer: the Framingham Study revisited. Am J Epidemiol. 1999;149: 93-101.

16. Feigelson HS, Calle EE, Robertson AS, Wingo PA, Thun MJ. Alcohol consumption increases the risk of fatal breast cancer (United States). Cancer Causes Control. 2001;12:895-902.

17. Dumeaux V, Lund E, Hjartaker A. Use of oral contraceptives, alcohol, and risk for invasive breast cancer. Cancer Epidemiol Biomarkers Prev. 2004;13:1302-7.

18. Horn-Ross PL, Canchola AJ, West DW, Stewart SL, Bernstein L, Deapen D, et al. Patterns of alcohol consumption and breast cancer risk in the California Teachers Study cohort. Cancer Epidemiol Biomarkers Prev. 2004;13:405-11.

19. Suzuki R, Ye W, Rylander-Rudqvist T, Saji S, Colditz GA, Wolk A. Alcohol and postmenopausal breast cancer risk defined by estrogen and progesterone receptor status: A prospective cohort study. J Nat Cancer Inst. 2005;97:1601-8.

20. Mellemkjaer L, Bigaard J, Tjonneland A, Christensen J, Thomsen B, Johansen C, et al. Body composition and breast cancer in postmenopausal women: a Danish prospective cohort study. Obesity. 2006;14:1854-62.

21. Tjonneland A, Christensen J, Olsen A, Stripp C, Thomsen BL, Overvad K, et al. Alcohol intake and breast cancer risk: the European Prospective Investigation into Cancer and Nutrition (EPIC). Cancer Causes Control. 2007;18:361-73.

22. Zhang SM, Lee IM, Manson JE, Cook NR, Willett WC, Buring JE. Alcohol consumption and breast cancer risk in the Women's Health Study. Am J Epidemiol. 2007;165:667-76.

23. Kabat GC, Miller AB, Jain M, Rohan TE. Dietary intake of selected $\mathrm{B}$ vitamins in relation to risk of major cancers in women. Br J Cancer. 2008;99:816-21.

24. Allen NE, Beral V, Casabonne D, Kan SW, Reeves GK, Brown A, et al. Moderate alcohol intake and cancer incidence in women. J Natl Cancer Inst. 2009;101:296-305. 
25. Lew JQ, Freedman ND, Leitzmann MF, Brinton LA, Hoover RN, Hollenbeck AR, et al. Alcohol and risk of breast cancer by histologic type and hormone receptor status in postmenopausal women: the NIH-AARP Diet and Health Study. Am J Epidemiol. 2009;170:308-17.

26. Li CI, Chlebowski RT, Freiberg M, Johnson KC, Kuller L, Lane $\mathrm{D}$, et al. Alcohol consumption and risk of postmenopausal breast cancer by subtype: the women's health initiative observational study. J Natl Cancer Inst. 2010;102:1422-31.

27. Chen WY, Rosner B, Hankinson SE, Colditz GA, Willett WC. Moderate alcohol consumption during adult life, drinking patterns, and breast cancer risk. JAMA. 2011;306:1884-90.

28. Kawai M, Minami Y, Kakizaki M, Kakugawa Y, Nishino Y, Fukao A, et al. Alcohol consumption and breast cancer risk in Japanese women: the Miyagi Cohort study. Breast Cancer Res Treat. 2011;128:817-25.

29. Liu Y, Colditz GA, Rosner B, Berkey CS, Collins LC, Schnitt SJ, et al. Alcohol intake between menarche and first pregnancy: a prospective study of breast cancer risk. J Natl Cancer Inst. 2013;105:1571-8.

30. Falk RT, Maas P, Schairer C, Chatterjee N, Mabie JE, Cunningham $C$, et al. Alcohol and risk of breast cancer in postmenopausal women: an analysis of etiological heterogeneity by multiple tumor characteristics. Am J Epidemiol. 2014;180: 705-17.

31. Park SY, Kolonel LN, Lim U, White KK, Henderson BE, Wilkens LR. Alcohol consumption and breast cancer risk among women from five ethnic groups with light to moderate intakes: the Multiethnic Cohort Study. Int J Cancer. 2014;134: 1504-10.

32. Chhim AS, Fassier P, Latino-Martel P, Druesne-Pecollo N, Zelek L, Duverger L, et al. Prospective association between alcohol intake and hormone-dependent cancer risk: modulation by dietary fiber intake. Am J Clin Nutr. 2015;102:182-9.

33. Hippisley-Cox J, Coupland C. Development and validation of risk prediction algorithms to estimate future risk of common cancers in men and women: prospective cohort study. BMJ Open. 2015;5:e007825.

34. Klatsky AL, Li Y, Nicole Tran H, Baer D, Udaltsova N, Armstrong MA, et al. Alcohol intake, beverage choice, and cancer: a cohort study in a large kaiser permanente population. Perm J. 2015; 19:28-34.

35. Shin A, Sandin S, Lof M, Margolis KL, Kim K, Couto E, et al. Alcohol consumption, body mass index and breast cancer risk by hormone receptor status: Women' Lifestyle and Health Study. BMC Cancer. 2015;15:881.

36. Nitta J, Nojima M, Ohnishi H, Mori M, Wakai K, Suzuki S, et al. Weight gain and alcohol drinking associations with breast cancer risk in Japanese postmenopausal women: results from the Japan Collaborative Cohort (JACC) study. Asian Pac J Cancer Prev. 2016;17:1437-43.
37. Chen K, Jiang Q, Ma X, Li Q, Yao K, Yu W, et al. Alcohol drinking and colorectal cancer: a population-based prospective cohort study in China. Eur J Epidemiol. 2005;20:149-54.

38. Thygesen LC, Wu K, Gronbaek M, Fuchs CS, Willett WC, Giovannucci E. Alcohol intake and colorectal cancer: a comparison of approaches for including repeated measures of alcohol consumption. Epidemiology. 2008;19:258-64.

39. Park JY, Mitrou PN, Dahm CC, Luben RN, Wareham NJ, Khaw KT, et al. Baseline alcohol consumption, type of alcoholic beverage and risk of colorectal cancer in the European Prospective Investigation into Cancer and Nutrition-Norfolk study. Cancer Epidemiol. 2009;33:347-54.

40. Everatt R, Tamosiunas A, Virviciute D, Kuzmickiene I, Reklaitiene R. Consumption of alcohol and risk of cancer among men: a 30 year cohort study in Lithuania. Eur J Epidemiol. 2013;28:383-92.

41. Cho S, Shin A, Park SK, Shin HR, Chang SH, Yoo KY. Alcohol drinking, cigarette smoking and risk of colorectal cancer in the Korean multi-center cancer cohort. J Cancer Prev. 2015;20: $147-52$.

42. Liu Y, Nguyen N, Colditz GA. Links between alcohol consumption and breast cancer: a look at the evidence. Womens Health (Lond). 2015;11:65-77.

43. Oyesanmi O, Snyder D, Sullivan N, Reston J, Treadwell J, Schoelles KM. Alcohol consumption and cancer risk: understanding possible causal mechanisms for breast and colorectal cancers. Evid Rep Technol Assess (Full Rep). 2010;(197):1-151.

44. Imhof A, Woodward M, Doering A, Helbecque N, Loewel H, Amouyel $\mathrm{P}$, et al. Overall alcohol intake, beer, wine, and systemic markers of inflammation in western Europe: results from three MONICA samples (Augsburg, Glasgow, Lille). Eur Heart J. 2004;25:2092-100.

45. Bianchini F, Vainio H. Wine and resveratrol: mechanisms of cancer prevention? Eur J Cancer Prev. 2003;12:417-25.

46. Rohrmann S, Linseisen J, Boshuizen HC, Whittaker J, Agudo A, Vineis $\mathrm{P}$, et al. Ethanol intake and risk of lung cancer in the European Prospective Investigation into Cancer and Nutrition (EPIC). Am J Epidemiol. 2006;164:1103-14.

47. Woodson K, Tangrea JA, Barrett MJ, Virtamo J, Taylor PR, Albanes D. Serum alpha-tocopherol and subsequent risk of lung cancer among male smokers. J Natl Cancer Inst. 1999;91: 1738-43.

48. Hong SH, Myung SK, Kim HS; Korean Meta-Analysis (KORMA) Study Group. Alcohol intake and risk of thyroid cancer: a meta-analysis of observational studies. Cancer Res Treat. 2017;49:534-47.

49. Scoccianti C, Cecchini M, Anderson AS, Berrino F, BoutronRuault MC, Espina C, et al. European Code against Cancer 4th Edition: alcohol drinking and cancer. Cancer Epidemiol. 2016;45: 181-8. 